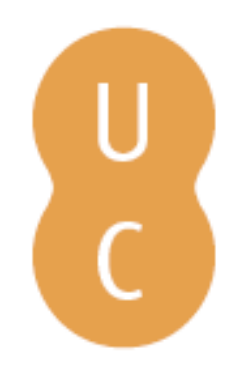

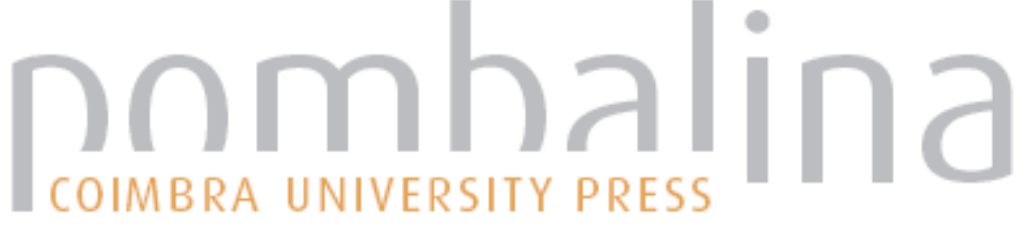

Ilha de Moçambique salubre e fresca em tempo de alterações climáticas

Autor(es): $\quad$ Vaz, João

Publicado por: Imprensa da Universidade de Coimbra

URL

persistente: URI:http://hdl.handle.net/10316.2/44318

DOI: $\quad$ DOI:https://doi.org/10.14195/978-989-26-1556-1_13

Accessed : $\quad$ 26-Apr-2023 16:08:05

A navegação consulta e descarregamento dos títulos inseridos nas Bibliotecas Digitais UC Digitalis, UC Pombalina e UC Impactum, pressupõem a aceitação plena e sem reservas dos Termos e Condições de Uso destas Bibliotecas Digitais, disponíveis em https://digitalis.uc.pt/pt-pt/termos.

Conforme exposto nos referidos Termos e Condições de Uso, o descarregamento de títulos de acesso restrito requer uma licença válida de autorização devendo o utilizador aceder ao(s) documento(s) a partir de um endereço de IP da instituição detentora da supramencionada licença.

Ao utilizador é apenas permitido o descarregamento para uso pessoal, pelo que o emprego do(s) título(s) descarregado(s) para outro fim, designadamente comercial, carece de autorização do respetivo autor ou editor da obra.

Na medida em que todas as obras da UC Digitalis se encontram protegidas pelo Código do Direito de Autor e Direitos Conexos e demais legislação aplicável, toda a cópia, parcial ou total, deste documento, nos casos em que é legalmente admitida, deverá conter ou fazer-se acompanhar por este aviso.

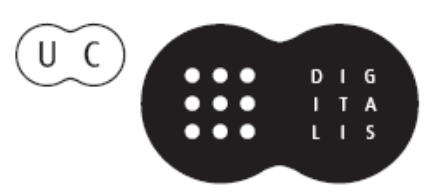




\section{OFICINAS DE \\ MUHIPITI \\ planeamento estratégico \\ património \\ desenvolvimento}

organização:

Walter Rossa

Nuno Lopes

Nuno Simão Gonçalves

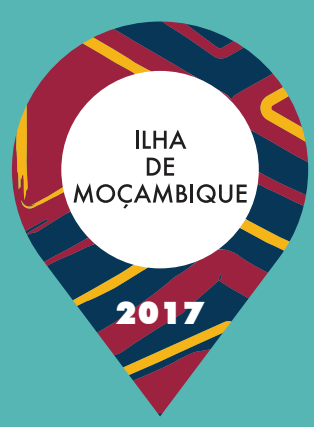




\title{
ILHA DE MOÇAMBIQUE SALUBRE E FRESCA EM TEMPO DE ALTERAÇÕES CLIMÁTICAS
}

\author{
João Vaz
}

\section{INTRODUÇÃO}

O património natural da llha de Moçambique está em risco e declínio. Por um lado, as preocupações do património concentram-se na recuperação de imóveis, por outro, evidencia-se um certo desinteresse pelos valores da conservação da flora e da fauna nativas.

Tanto em terra como no mar esses sinais de perda são evidentes, em especial naquilo que o visitante atento observa facilmente, porque está perto e é visível: há muito lixo nas praias, desde garrafas de plástico até restos de redes mosquiteiras abandonadas; as motos de água, ao fim de semana, afugentam um capital natural muito valioso, a vida marinha de proximidade, desde as baleias que se aproximam do pontão até às pessoas que desejam apenas dar um mergulho; os pequenos peixes tropicais que circundam a embarcação afundada no pontão são capturados por pescadores amadores; a erosão começa a sentir-se na contracosta, o mar bate com mais força e os muros de contenção estão a colapsar. Falta um plano para rearborizar a Ilha, substituindo árvores envelhecidas precocemente por sucessivas podas mal conduzidas, com destruição da copa; para além da situação da salubridade e da gestão de resíduos, onde existem esforços visíveis de limpeza da llha, muito do lixo continua a ser enterrado na areia e não existe valorização material. Os desafios são imensos e só serão ultrapassados se a sociedade civil se mobilizar e pressionar o poder político a agir de forma mais persistente.

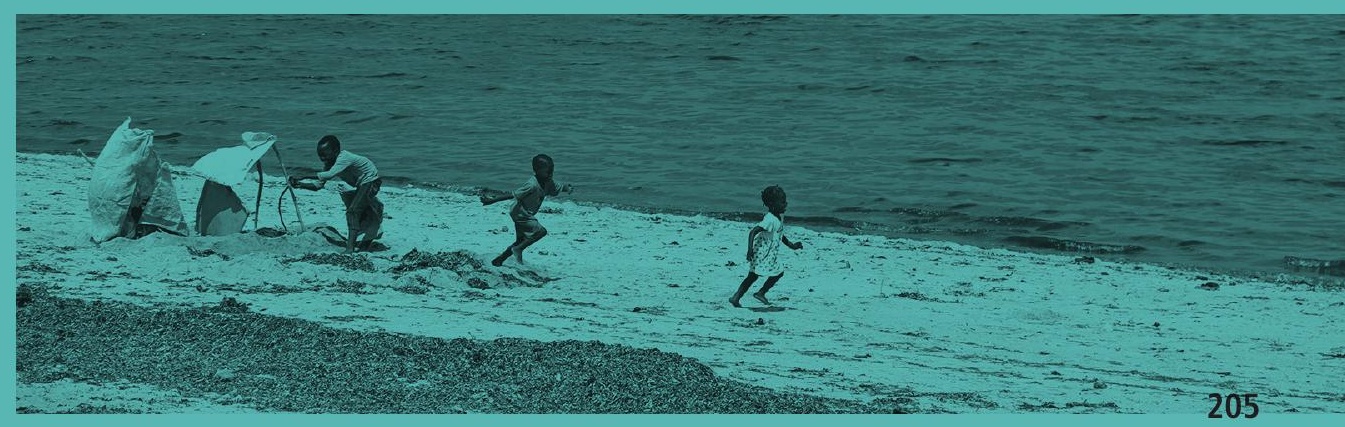




\section{2. ÁRVORES QUE VALORIZAM A ILHA}

Há poucos locais no mundo onde a beleza patrimonial seja tão reconhecidamente magnífica, coexistindo com uma riqueza natural tão diversificada. Começar a valorizar as árvores da llha é "classificar as maiores árvores de interesse público é evidenciá-las, protegê-las e estimular outros a preservar as árvores mais antigas, que carregam a história e a memória dos que com elas conviveram ou convivem." (Lage, 2008a: 35).

É necessário explicar à população o seu valor e interesse, começando pelas escolas. E aqui um parêntese para afirmar a ausência de conhecimento nesta área: as crianças e os próprios jardineiros não sabem identificar as árvores pelo nome e desconhecem qual a sua importância ecológica. As árvores são mal entendidas: sujam, ameaçam as casas, podem cair, são maltratadas. Essa evidência ganha força quando falamos com os decisores sobre as podas das árvores dos espaços urbanos que estão mal informados e continuam a podar radicalmente as árvores, destruindo a copa, secando-as a prazo.

Parece estar esquecida a absoluta importância das árvores em climas tropicais, amenizando a temperatura, emprestando sombra e contribuindo para a valorização estética dos espaços urbanos. Os técnicos precisam de apropriar-se desta ideia e de obter formação sobre a manutenção de árvores em espaços urbanos. As árvores devem ser podadas com técnica, ficando com parte dos seus ramos prontos a trabalhar, purificando o ar e oferecendo uma refrescante sombra quando o sol queima.

Falta um programa de substituição e plantação de novas árvores. A ameaça à ideia de plantação de árvores é evidente na observação dos espaços das caldeiras das árvores: são tapados com cimento, decerto por facilitismo, talvez por insensibilidade. É preciso criar ainda programas de sombra natural para a cidade de macuti, onde quase não há sombras e as casas forradas a chapa de zinco aquecem muito, com todos os problemas sanitários daí decorrentes. Contudo, antes de se plantar uma árvore deve avaliar-se o espaço que lhe queremos destinar, procurando plantar árvores locais. Citando um especialista na matéria, "As árvores sabem como interagir com equilíbrio com as demais árvores, arbustos e ervas do tecido vegetal local, estão bem integradas há milhares de anos" (Lage, 2008: 42). 


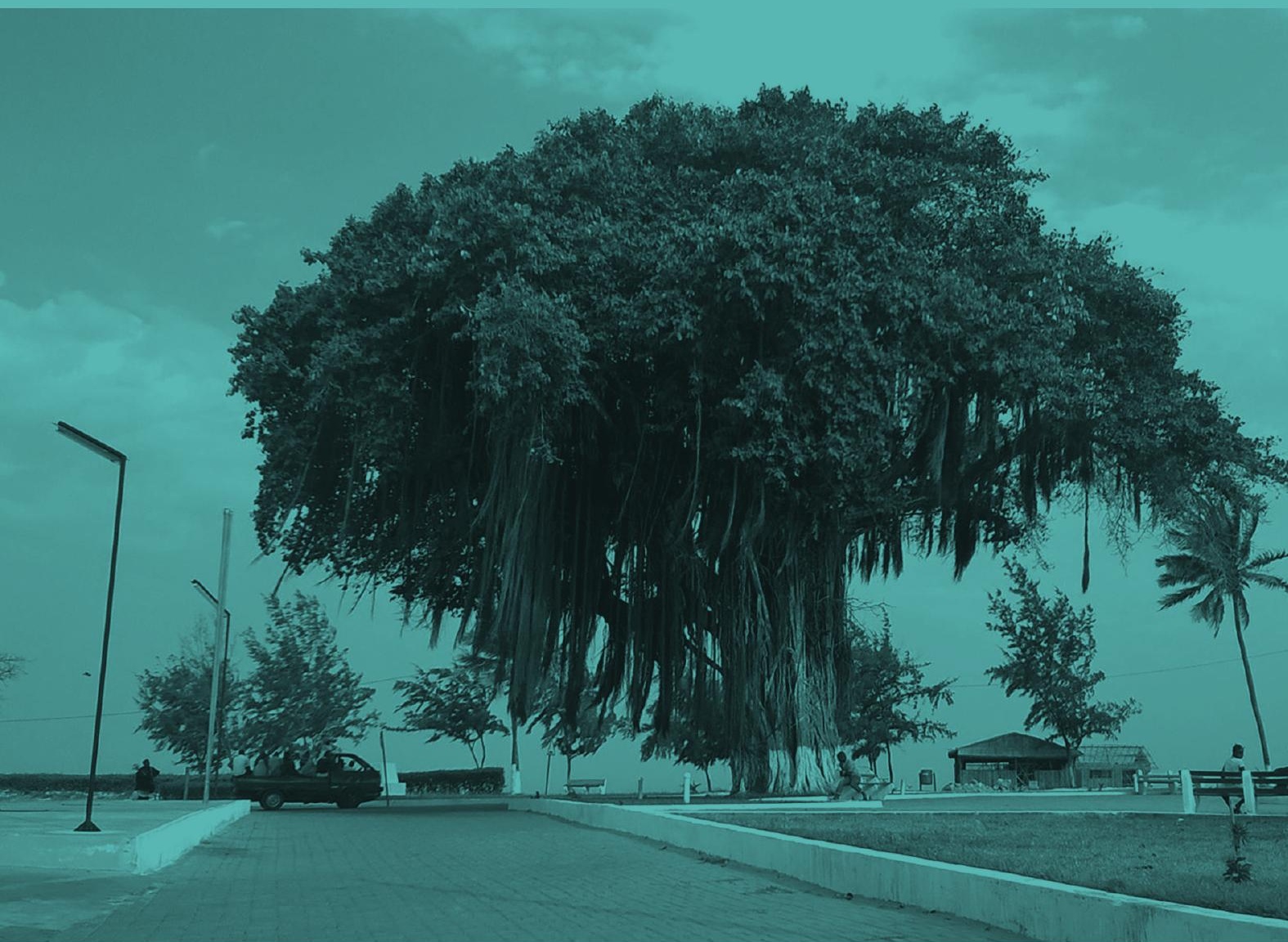

O biólogo Jorge Paiva, em A Relevância das Árvores das Artérias Urbanas, refere-nos que "uma cidade além de ser uma parcela integrada da paisagem, não deve constituir apenas um agregado de blocos de betão [pedra] separados por arruamentos asfaltados [cimentados, impermeabilizados], sem quaisquer espaços verdes, nem árvores ou arbustos nas respetivas artérias" (apud Lage, 2008: 42). Sabemos ainda que o clima está a mudar e as árvores são uma parte importante da solução, mitigando as ondas de calor, contribuindo para que a temperatura nos espaços urbanos seja mais amena. 


\section{FECALISMO, SALUBRIDADE E LIMPEZA DE PRAIAS}

O fecalismo a céu aberto nas praias da llha é considerado a maior ameaça à qualidade das praias. Apesar desta triste realidade persistir há dezenas de anos, as soluções não têm funcionado bem. Os sanitários são poucos, de má qualidade construtiva e muito insalubres. Tudo se resume a maus projetos. A abordagem que defendo para os sanitários, e a eliminação da necessidade da população usar a praia como casa de banho, passa por duas medidas simples, mas difíceis: privatizar os balneários e demolir os existentes. As pessoas estão dispostas a pagar 2 a 5 meticais por uso para ter condições de higiene, com banho e água salubre. Sabemos ainda da dificuldade e maus resultados dos municípios assumirem a gestão direta de equipamentos, pois tudo funciona melhor se houver geração de receita e gestão privada dos equipamentos e, ainda assim, é necessária fiscalização, empenho, apoio técnico e uma enorme persistência até que se possa verificar uma gradual mudança de hábitos.

A limpeza das praias enferma de uma incompreensão sobre o que é limpar e o que é lixo que precisa de ser limpo. Hoje, enterra-se o lixo na praia. As pessoas encarregadas da limpeza diária das praias (cerca de 13 pessoas, 6 dias por semana das 5 h00 às 9h00), gastam muita energia, tempo e dinheiro para esconderem temporariamente o lixo debaixo da areia. Plásticos (oleados e galões, como se diz na llha), descartáveis (fraldas), latas, roupa, redes mosquiteiras, vidros, calçado, filtros de óleo, pilhas e milhares de outros objetos antropogénicos ficam na praia e no mar. Vão e voltam, andam a pairar à volta da Ilha, de praia em praia, até se desfazerem e persistirem sob a forma de micropartículas poluidoras, envenenando o mar e enchendo o estômago de aves e peixes que, com a sensação de estarem saciados, deixam de se alimentar, causando a morte por subnutrição.

Limpar as praias na llha teria um efeito económico muito sensível. As praias urbanas de qualidade são raras e muito apetecidas. Os turistas ficariam mais dias na llha se tivessem praias limpas, sem plásticos nem excrementos. As autoridades locais não entenderam isto na sua plenitude, talvez por não frequentarem as praias urbanas e não conseguirem compreender os desejos dos turistas e visitantes. 
São necessárias ações de sensibilização na área de gestão das praias, a começar pelos decisores e técnicos, levando-os ao terreno para compreenderem os principais problemas. Importa, por fim, a interiorização de que algas marinhas, folhas e outras formas naturais de vida do Oceano Índico não são lixo. Uma praia cheia de algas na zona intermareal é normal e aceitável. Contudo, muitos decisores julgam que uma praia limpa é aquela que está vazia de algas e plantas, ignorando muitas vezes até o que realmente interessa limpar, isto é, o lixo que é lixo: os plásticos, as garrafas e tudo aquilo que não é natural. Os presidentes e vereadores, os chefes de posto e régulos, são necessariamente aqueles de que mais capacitação necessitam, porque têm o poder direto na influência de práticas e costumes, combatendo de forma mais eficaz a insalubridade do espaço público.

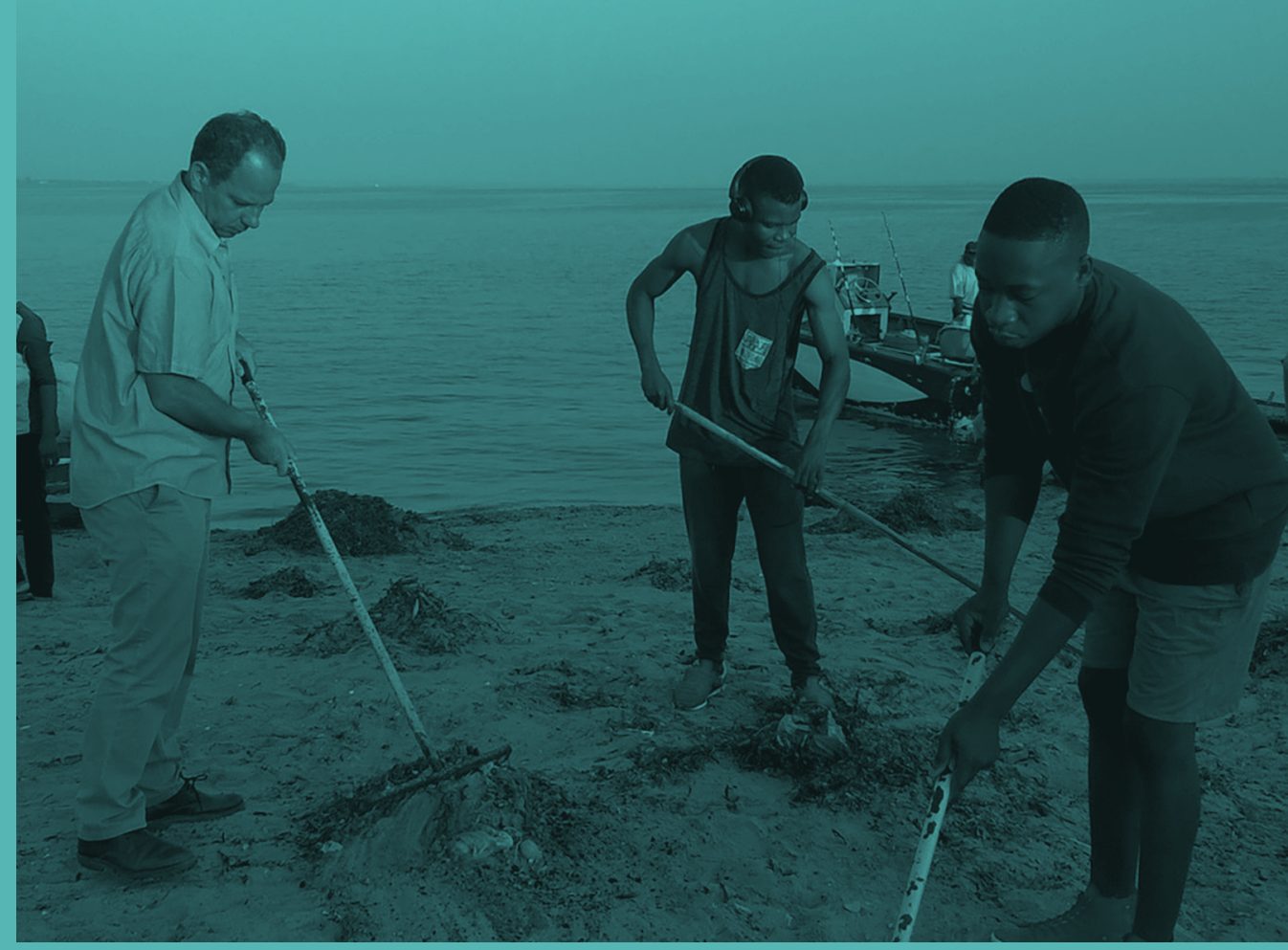


Seria possível ir mais longe na limpeza da llha e do planeta, pagando a quem recolhe lixo pela quantidade e qualidade do que é removido da praia e do mar. A llha poderia ser pioneira neste campo, mais ainda se reaproveitasse esse mesmo lixo para o artesanato, criando uma verdadeira fileira de bens, inovando e dando emprego a muitos jovens desocupados. Tudo isto precisa de ser financiado internamente e externamente. Acredito que haverá forma de o fazer com sucesso, bastará persistir e mostrar à comunidade internacional que a llha é vítima de quem fabrica "fraldas descartáveis, com materiais que não são biodegradáveis, numa lógica onde impera o lucro e não o bem comum" (Vaz, 2014). A este propósito, refira-se que os mergulhadores profissionais da llha se queixam frequentemente da existência de fraldas de plástico agarradas ao fundo do mar, impedindo os corais de respirar e, na prática, asfixiando a base da vida marinha.

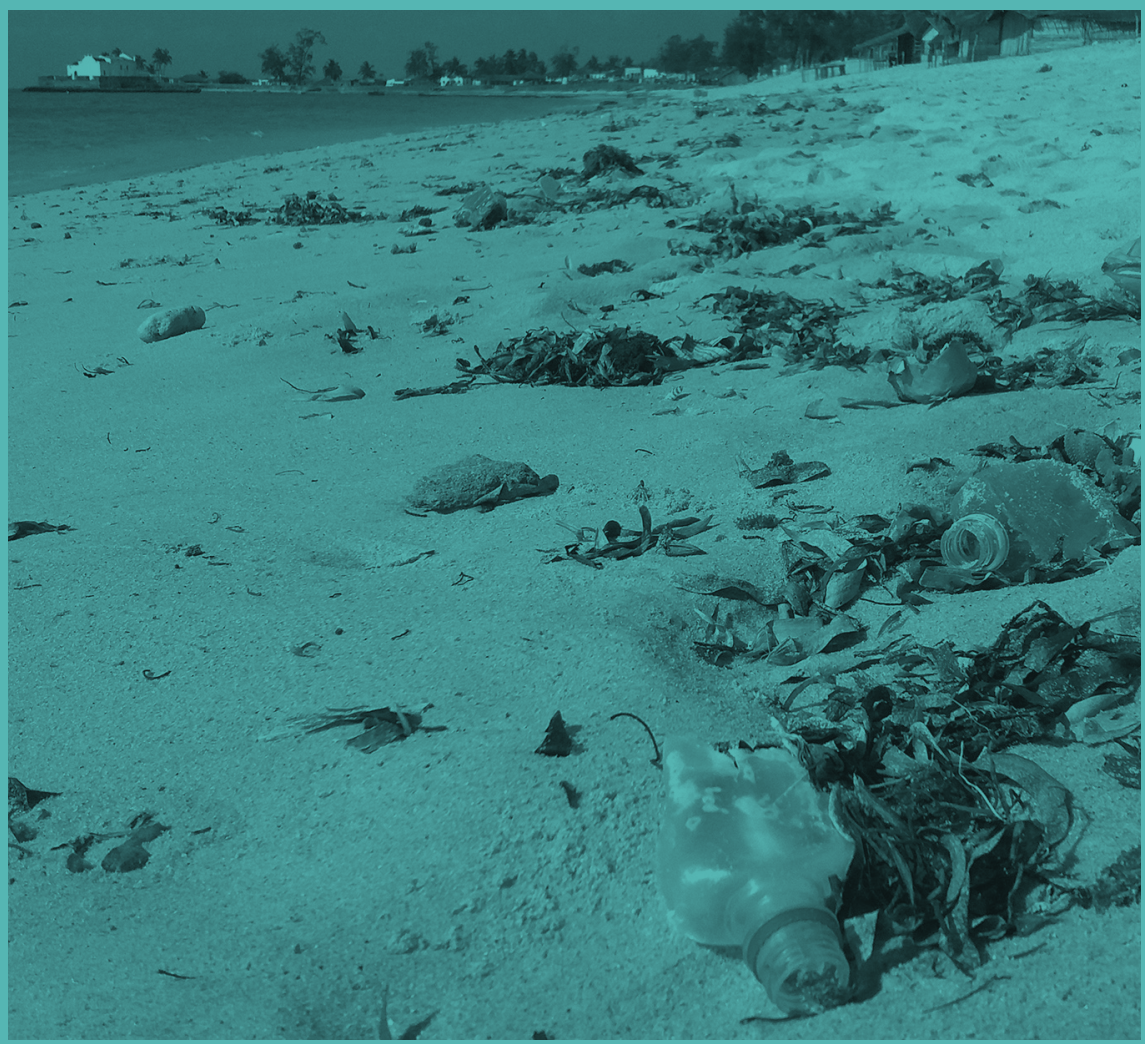




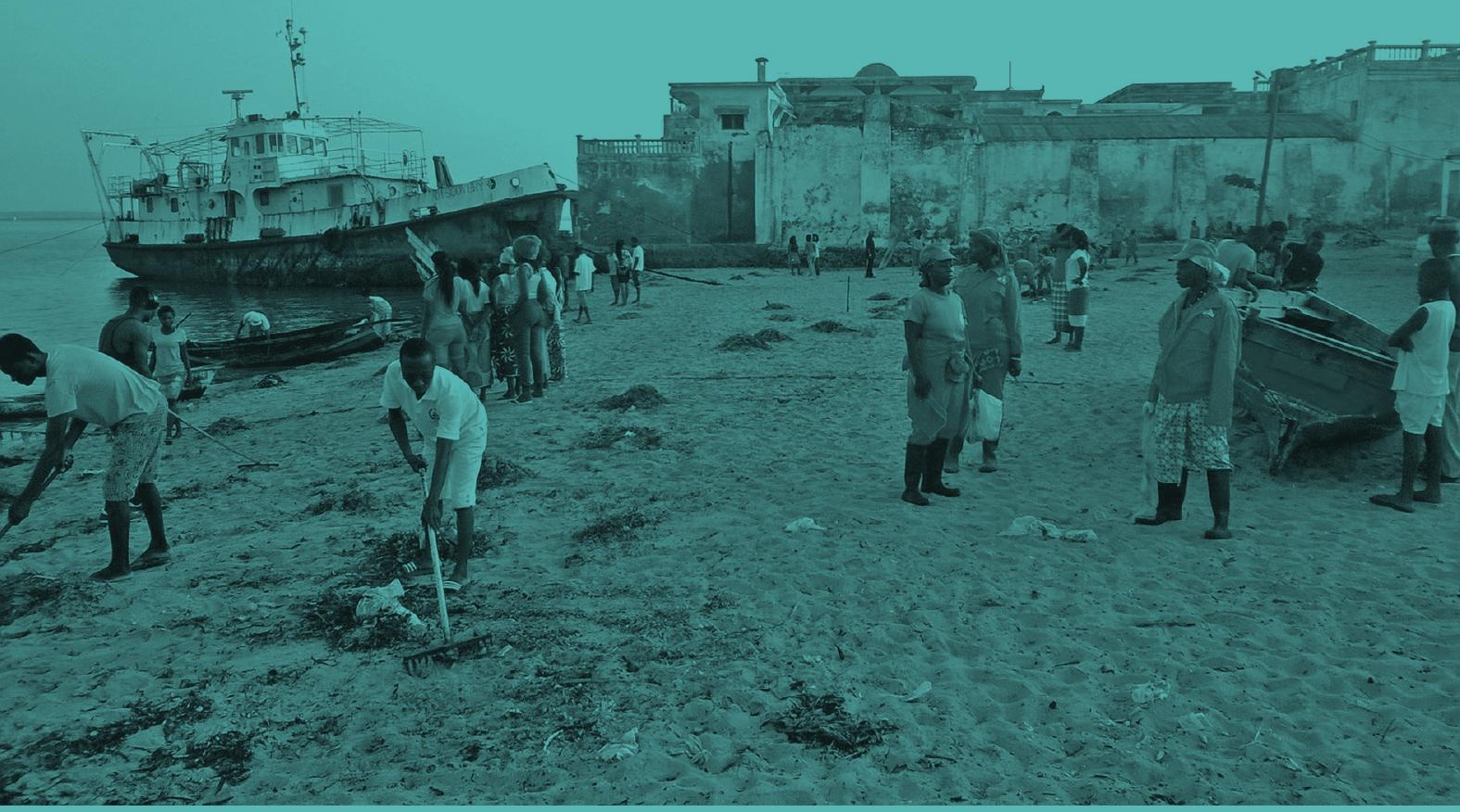

\section{A GESTÃO DE RESÍDUOS}

A salubridade do habitante médio da Ilha é reconhecida, existem preocupações visíveis com a limpeza dos espaços privados. As pessoas começam o dia, às 5h00, a varrer o quintal e a colocar o lixo fora de casa para que este seja recolhido. O espaço privado, em geral, está limpo e bem cuidado. Já o espaço público carece de outra abordagem. Aqui, o lixo é por vezes enterrado em buracos entre as casas, a pedido das pessoas. Varre-se o lixo para o buraco e espera-se que este venha a desaparecer. A parte orgânica, sim, desaparece, mas tudo o resto permanecerá muitos anos. O trator do lixo desvia-se frequentemente da sua rota para despejar resíduos domésticos e comerciais em fundações de futuras casas. Esta realidade, chocante para quem compreende os efeitos indesejáveis na casa e sua salubridade, é adotada na Ilha, sobretudo na parte continental, como prática habitual. O lixo é um fenómeno cultural e daí a sua gestão ter que se adaptar à realidade que encontramos. Contudo, as pessoas têm que ter locais para colocar o lixo, baldes, tambores, contentores, etc., o que não acontece com a frequência e conforto desejáveis. Ninguém anda mais de 200 metros com o lixo para o despejar no sítio certo. Se não encontra sítio, deixa-o em qualquer lugar. Verifica-se, portanto, a necessidade de a llha investir muito mais na recolha primária, nos baldes e contentores, podendo responsabilizar mais as pessoas. 


\section{VISÃO PARA A ILHA}

Na llha há um investimento real na recolha do lixo: o sistema de apito, em que o trator do lixo passa e leva o lixo das pessoas. Funciona bem, mas poderia ser mais ambicioso e abrangente, contando com a colaboração da população na separação do lixo em duas frações: seca e húmida. Existem já projetos de aproveitamento da parte húmida, restos de comida, cascas de feijão, cana-de-açúcar, folhas e ramos, etc., através da compostagem doméstica, transformando lixo em adubo natural. Este projeto, suportado financeiramente pela Cooperação Portuguesa, resultou bem na parte continental do município da llha de Moçambique. Contudo, precisa de um apoio mais continuado. A gestão de resíduos precisa de intervenção do Estado, uma vez que não há capacidade financeira em locais sem dimensão económica.

A visão passa também pelo apoio à machamba (terreno agrícola), a microcultura de bens alimentares capazes de gerar algum rendimento extra para as famílias carenciadas da Ilha. Este esforço passa pela existência de sementes, adubo e capacidade técnica. O adubo poderá ser suprido pela transformação doméstica e comunitária dos resíduos em fertilizante natural. A organização deste tipo de iniciativas inovadoras, criando o slogan "uma família, um compostor e uma machamba", necessita de programas de capacitação e de apoio económico direto para uma fase inicial. O sucesso de um modelo de compostagem 
depende ainda da capacidade do Conselho Municipal da llha de Moçambique [CMIM] em usar o composto (fertilizante natural) nos seus próprios verdes. Segundo o atual presidente do CMIM, a relva dos jardins municipais "está mais verde que a do Estádio do Benfica", vangloriando-se assim, e bem, do seu município ter o que outros não conseguem: espaços verdes de qualidade.

A llha necessita de uma estação de compostagem e processamento de resíduos no próprio território, evitando custos de transporte e o desgaste que é atravessar a ponte. São apenas necessários 1.000 a 2.000 metros quadrados. Sem a necessidade de tecnologias de ponta, mas com conhecimento e reproduzindo experiências bem-sucedidas de outros países nesta matéria. A llha poderia ser um centro de excelência, um modelo de como fazer gestão de resíduos que servisse de inspiração ao resto do país. Existem países disponíveis e capazes de apoiar este tipo de projetos. Há também quadros técnicos, a serem formados no país, capazes de abraçar os desafios emergentes.

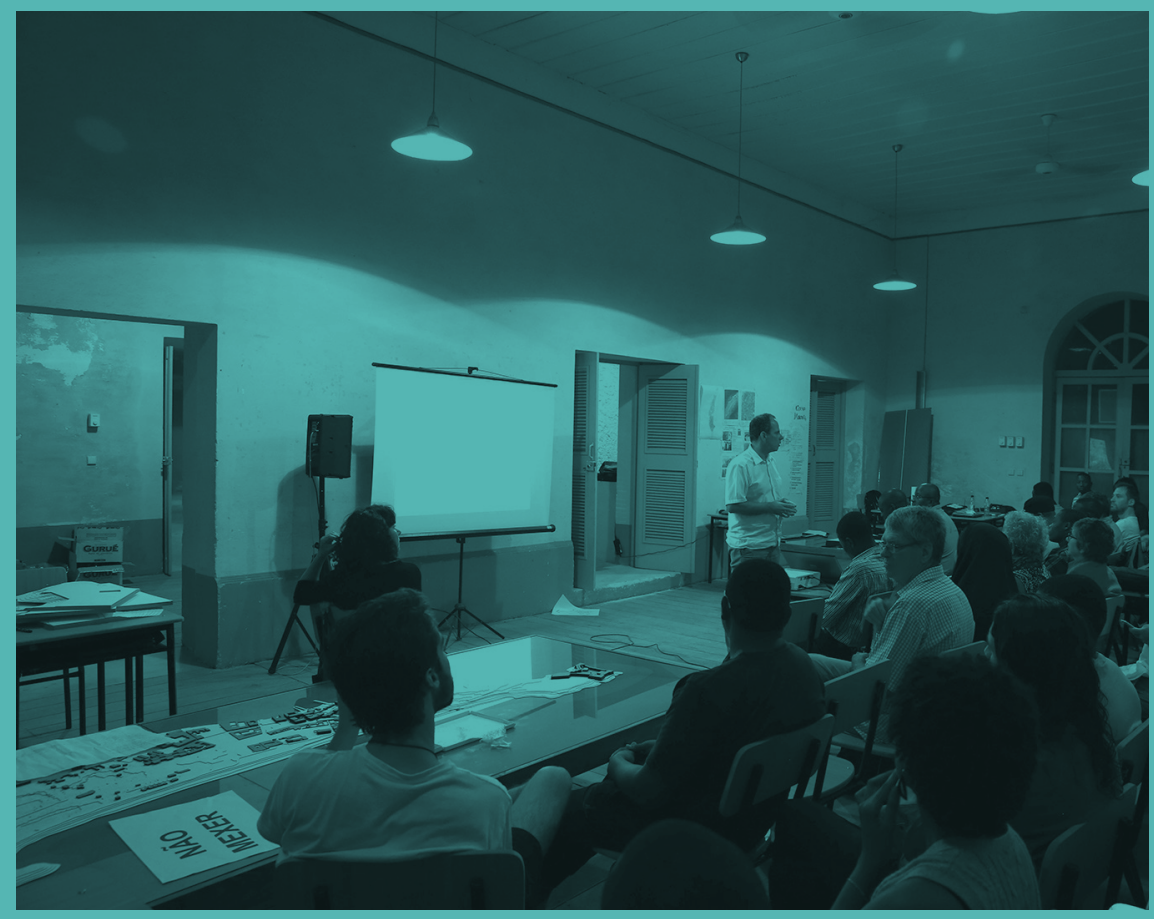




\section{CONCLUSÃO}

A llha de Moçambique é um espaço de uma riqueza única do ponto de vista ambiental, ameaçado pela insensibilidade de uns, desconhecimento de outros, e, ainda, por um novo-riquismo incapaz de perceber a harmonia e as potencialidades deste território. Somos nós (técnicos, investigadores, turistas, visitantes, professores, arquitetos, historiadores, lojistas, artistas, engenheiros, líderes religiosos, empresários, agricultores, jornalistas, cooperantes) que, em conjunto com a população, nos deveremos dedicar à necessária valorização deste Património Mundial, para que seja mais digno da nossa presença, mais sustentável, e um dos melhores locais do mundo para residir, viver e visitar. Sem lixo nas praias, com árvores bem formadas, muita sombra e resiliência às alterações climáticas.

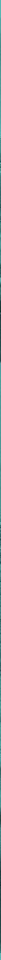




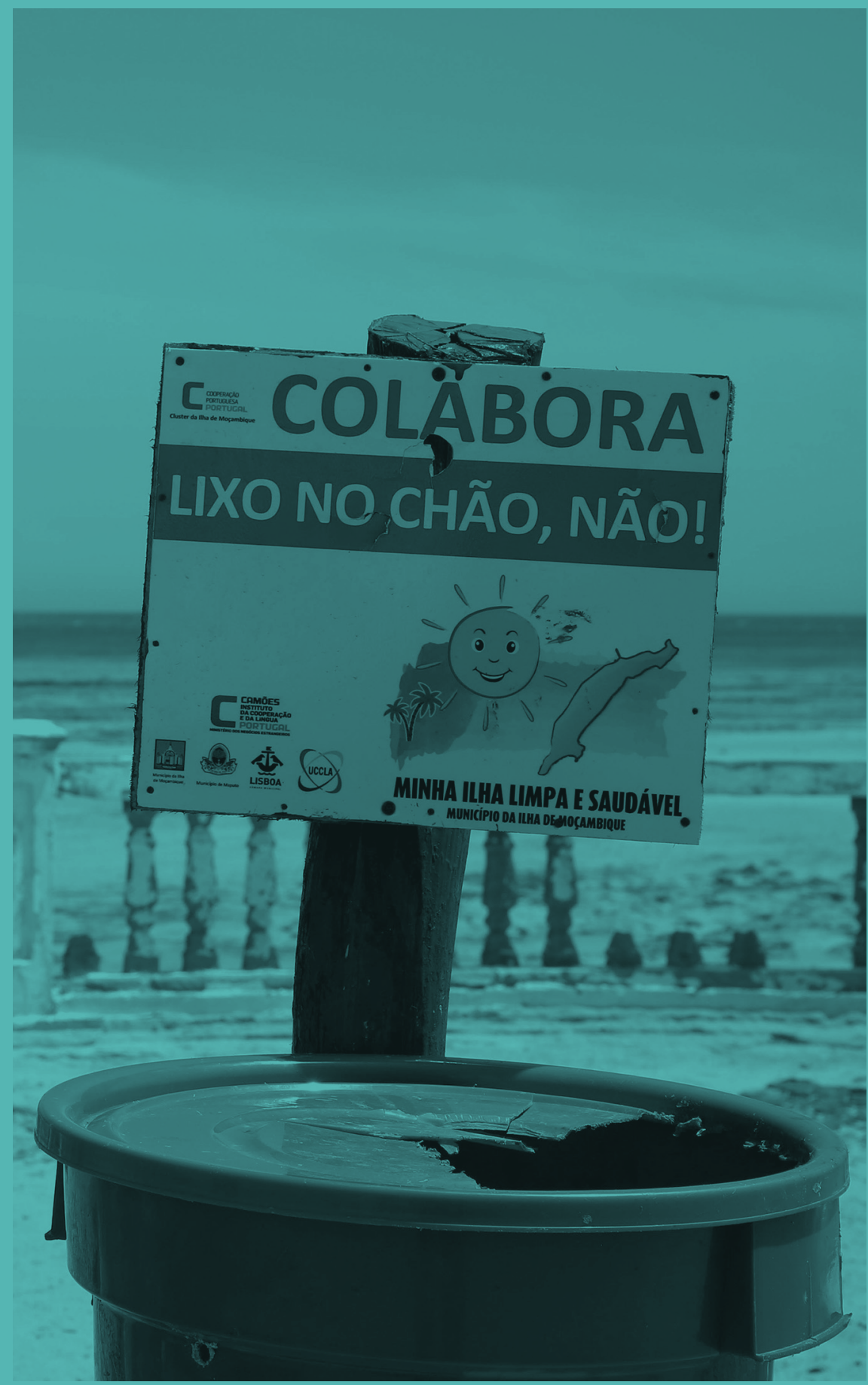




\section{REFERÊNCIAS BIBLIOGRÁFICAS}

LAGE, Jorge (2008), "A biodiversidade é riqueza", TER, revista da Escola Profissional Terra Verde, 2, 42-43.

LAGE, Jorge (2008a), "As Árvores nos Espaços Urbanos", TER, revista da Escola Profissional Terra Verde, 3, 35-36.

PAIVA, Jorge (1999), "Coimbra: as artérias urbanas e as árvores", Cadernos de Geografia - Actas do primeiro colóquio de geografia de Coimbra, 1996, número especial, 49-56. Coimbra: Instituto de Estudos Geográficos, com a colaboração do Centro de Estudos Geográficos, Faculdade de Letras da Universidade de Coimbra.

VAZ, João (2014), "O lixo nos nossos mares". Agência Europeia do Ambiente, consultado a 22.04.2016 em https://www.eea.europa.eu/pt/sinais-daaea/sinais-2014/em-analise/o-lixo-nos-nossos-mares 